\title{
Heat Transfer Enhancement and Hydrodynamic Characteristics of Nanofluid in Turbulent Flow Regime
}

\author{
Mohammad Nasiri-lohesara \\ Department of Mechanical Engineering, Babol University of Technology, Shariati Street, Babol 47148-71167, Iran \\ Correspondence should be addressed to Mohammad Nasiri-lohesara; m.nasiri.lohesara@gmail.com
}

Received 19 September 2014; Accepted 15 January 2015

Academic Editor: Guobing Zhou

Copyright (C) 2015 Mohammad Nasiri-lohesara. This is an open access article distributed under the Creative Commons Attribution License, which permits unrestricted use, distribution, and reproduction in any medium, provided the original work is properly cited.

\begin{abstract}
Turbulent forced convection of $\gamma-\mathrm{Al}_{2} \mathrm{O}_{3}$ /water nanofluid in a concentric double tube heat exchanger has been investigated numerically using mixture two-phase model. Nanofluids are used as coolants flowing in the inner tube while hot pure water flows in outer tube. The studies are conducted for Reynolds numbers ranging from 20,000 to 50,000 and nanoparticle volume fractions of 2, 3, 4, and 6 percent. Results showed that nanofluid has no effects on fully developed length and average heat transfer coefficient enhances with lower slope than wall shear stress. Comparisons with experimental correlation in literature are conducted and good agreement with present numerical study is achieved.
\end{abstract}

\section{Introduction}

With progresses of technology heat transfer augmentation is one of the most challenges for developing Hi-tech industries.

Application of additives to liquids is one way of enhancing heat transfer. Augmenting of fluid thermal conductivity is the main purpose in improvement of the heat transfer characteristic of liquids.

Recently progress in material engineering and developing new technologies cause the basis of producing nanosized particles. Masuda et al. [1] introduced the liquid suspension of nanosized particles and then Choi [2] for the first time proposed the name of nanofluid to this suspension. Nanofluids change the thermal and hydraulic feature of base fluids and cause enormous heat transfer enhancement.

Many researcher investigated the thermophysical properties of nanofluid $[3,4]$. But research about the forced convection of nanofluids is important for the practical application of nanofluids in heat transfer devices. For this purpose different papers focused on the nanofluids convection experimentally and numerically.

Pak and Cho [5] investigated experimentally the convective heat transfer inside a circular tube. They investigated the convective heat transfer of $\gamma-\mathrm{Al}_{2} \mathrm{O}_{3}(13 \mathrm{~nm}) /$ water and $\mathrm{TiO}_{2}$
$(27 \mathrm{~nm}) /$ water nanofluids in the turbulent flow regime. Constant wall heat flux boundary condition was considered in the analysis. It was indicated that the heat transfer enhancement obtained with $\gamma-\mathrm{Al}_{2} \mathrm{O}_{3}$ particles is higher than that obtained with $\mathrm{TiO}_{2}$ particles. They proposed a new correlation for Nusselt number.

$\mathrm{Li}$ and Xuan [6] presented experimental study to investigate the heat transfer coefficient and friction factor of $\mathrm{Cu}$ /water nanofluid in both laminar and turbulent flow regimes up to $2 \%$ volume concentration. Constant wall heat flux boundary condition was exposed and observed Nusselt enhancements up to $60 \%$ with $2 \%$ volume concentration. It was seen that the heat transfer coefficient enhancement ratio (heat transfer coefficient of nanofluid divided by the heat transfer coefficient of base fluid) increases with increasing Reynolds number.

Maïga et al. [7] numerically studied laminar and turbulent force convection inside a circular tube under constant wall heat flux boundary condition. They used single-phase assumption and simulate the nanofluids of $\mathrm{Al}_{2} \mathrm{O}_{3}$ /water and $\mathrm{Al}_{2} \mathrm{O}_{3}$ /ethylene glycol, showing that the wall shear stress and heat transfer enhance with increasing volume fraction while the latter nanofluid showed better heat transfer enhancement in identical Reynolds number and volume fraction. 
Bianco et al. considered the laminar [8] and turbulent [9] flow of $\mathrm{Al}_{2} \mathrm{O}_{3} /$ water nanofluid under constant and uniform heat flux at the wall. They analyzed the problem by using both single- and two-phase models. The results showed heat transfer enhances with increasing particles volume concentration and Reynolds number and it showed that two-phase models for the simulation of nanofluid are satisfactory with comparing of experimental data.

In this study turbulent heat transfer and hydrodynamic characteristic of $\gamma-\mathrm{Al}_{2} \mathrm{O}_{3}$ /water nanofluid have been investigated using mixture two-phase model. Nanofluid flows in the inner tube while hot pure water flows in the outer tube. The analyses are conducted for different Reynolds numbers and volume fractions ranging from 20,000 to 50,000 and 2, 3, 4, and 6 percent, respectively. For validation of the numerical solution, the results are compared with Pak and Cho [5] correlation. The aim of this study is to add more contribution to turbulent convection heat transfer using nanofluid.

\section{Physical Model and Mathematical Modelling}

Figure 1 shows the considered configuration cross-section consisting of the double tube counterflow heat exchanger with a length of $0.65 \mathrm{~m}$ and with inner and outer diameter of $0.01 \mathrm{~m}$ and $0.015 \mathrm{~m}$, respectively. Nanofluids that enter the inner tubes are composed of $\gamma-\mathrm{Al}_{2} \mathrm{O}_{3}$ /water with mean particle diameter of $20 \mathrm{~nm}$. Table 1 shows the thermophysical properties of base fluid and nanoparticle.

Nanofluid thermophysical properties play important role in accuracy of the results. For density of nanofluids the following equation has been used [5]:

$$
\rho_{\mathrm{eff}}=(1-\phi) \rho_{b f}+\phi \rho_{p}
$$

Also specific heat of nanofluid is achieved by the following equation [10]:

$$
c_{\text {peff }}=\frac{(1-\varphi)\left(\rho c_{p}\right)_{b f}+\varphi\left(\rho c_{p}\right)_{p}}{(1-\varphi) \rho_{b f}+\varphi \rho_{p}} .
$$

Chon et al. [11] proposed a correlation for thermal conductivity. Correlation equation (2), except the volume fraction and particles diameter, considers the temperature and Brownian motion which is defined as follows:

$$
\begin{aligned}
\frac{k_{\mathrm{eff}}}{k_{f}}= & 1+64.7 \times \phi^{0.746} \times\left(\frac{d_{b f}}{d_{p}}\right)^{0.369} \\
& \times\left(\frac{k_{p}}{k_{f}}\right)^{0.746} \times \operatorname{Pr}^{0.9955} \times \operatorname{Re}^{1.2321},
\end{aligned}
$$

where Prandtl and Brownian Reynolds numbers are expressed as follows:

$$
\operatorname{Pr}=\frac{\mu}{\rho_{f} \alpha_{f}}, \quad \operatorname{Re}=\frac{\rho_{f} k_{b} T}{3 \pi \mu^{2} L_{f}},
$$

TABLE 1: Thermophysical properties of material under consideration.

\begin{tabular}{lccc}
\hline Materials & Density $\left(\mathrm{kg} / \mathrm{m}^{3}\right)$ & $\begin{array}{c}\text { Thermal } \\
\text { conductivity } \\
(\mathrm{W} / \mathrm{m} \mathrm{K})\end{array}$ & $\begin{array}{c}\text { Specific heat } \\
(\mathrm{J} / \mathrm{kg} \mathrm{K})\end{array}$ \\
\hline Water & 1000 & 0.6 & 4179 \\
$\gamma-\mathrm{Al}_{2} \mathrm{O}_{3}$ & 3880 & 36 & 773 \\
\hline
\end{tabular}

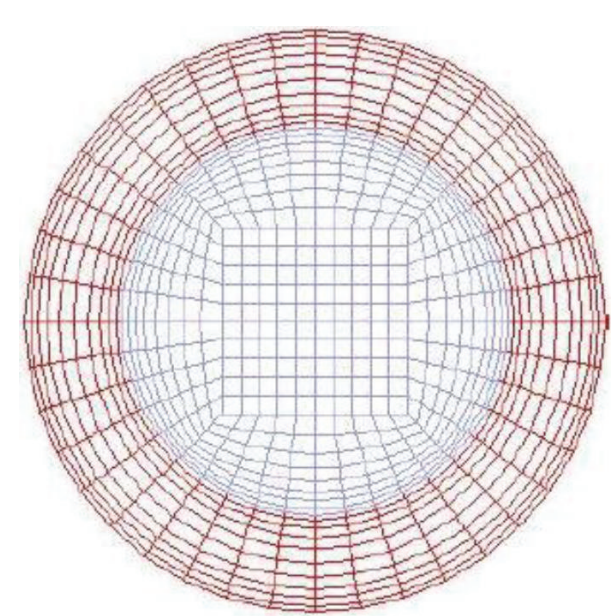

FIGURE 1: Geometrical configuration for present study.

where $L_{f}$ is the base fluid mean free path $(0.17 \mathrm{~nm}$ for water $)$ and $\mu$ is temperature-dependent viscosity of the base fluid which is defined as

$$
\mu=A \times 10^{B /(T-C)}
$$

The constants $A, B, C$ for water are equal to $2.414 * 10^{-5}, 247$, and 140 , respectively.

One equation for effective dynamic viscosity of nanofluid is defined as

$$
\frac{\mu_{\mathrm{nf}}}{\mu_{b f}}=123 \phi^{2}+7.3 \phi+1 .
$$

Equation (6) was obtained by [7] with cure fitting based on experimental data of Wang et al. [12].

Mixture model is used for modelling of nanofluid. This model solves continuity, momentum, and energy equations for the mixture as well as the volume fraction equation for the secondary phase and algebraic expression for the relative velocities (slip velocities). With neglecting dissipation and pressure work and for steady state the governing equations for this model are expressed as follows.

Continuity equation:

$$
\nabla \cdot\left(\rho_{\text {eff }} \vec{V}_{\text {mix }}\right)=0 .
$$

Momentum equation:

$$
\begin{aligned}
\nabla \cdot\left(\rho_{\text {eff }} \vec{V}_{\text {mix }} \vec{V}_{\text {mix }}\right)= & -\nabla P+\nabla \cdot\left(\mu_{\text {eff }}\left(\nabla \vec{V}_{\text {mix }}+\nabla \vec{V}_{\text {mix }}{ }^{T}\right)\right) \\
& +\nabla \cdot\left(\sum_{k=1}^{n} \phi_{k} \rho_{k} \vec{V}_{d r, k} \vec{V}_{d r, k}\right) .
\end{aligned}
$$


Energy equation:

$$
\nabla \cdot \sum_{k=1}^{n}\left(\phi_{k} V_{k}\left(\rho_{k} E_{k}+P\right)\right)=\nabla \cdot\left(k_{\mathrm{eff}} \nabla T\right) .
$$

Volume fraction:

$$
\nabla \cdot\left(\phi_{p} \rho_{p} \vec{V}_{\text {mix }}\right)=-\nabla \cdot\left(\phi_{p} \rho_{p} \vec{V}_{d r, p}\right),
$$

where $\vec{V}_{d r, k}=\vec{V}_{k}-\vec{V}_{\text {mix }}$ is the drift velocity for the secondary phase and it is related to slip velocity by the following equation:

$$
\vec{V}_{d r, p}=\vec{V}_{p f}-\sum_{k=1}^{n} \frac{\phi_{k} \rho_{k}}{\rho_{m}} \vec{V}_{f k}
$$

Manninen et al. [13] proposed an equation for calculating slip velocity equation (13). For determining the drag coefficient Schiller and Naumann [14] equation is used from (14):

$$
\begin{gathered}
\vec{V}_{p f}=\frac{\rho_{f} d_{p}^{2}}{18 \mu_{q}} \cdot \frac{\left(\rho_{p}-\rho_{\text {mix }}\right)}{f_{\text {drag }} \rho_{p}} \vec{a}, \\
f_{\text {drag }}= \begin{cases}1+0.15 \operatorname{Re}^{0.687}, & \operatorname{Re} \leq 1000, \\
0.0183 \operatorname{Re}, & \operatorname{Re} \geq 1000,\end{cases}
\end{gathered}
$$

where

$$
\operatorname{Re}_{p}=\frac{V_{\text {mix }} d_{p}}{v_{\text {eff }}} .
$$

From (13) the acceleration is given as

$$
\vec{a}=g-\left(\vec{V}_{\text {mix }} \cdot \nabla\right) \vec{V}_{\text {mix }} .
$$

Standard $k-\varepsilon$ two-equation eddy-viscosity model is used for closing the above governing equations. This model is proposed by Lauder and Spalding [15] and it is based on the solution of equations for turbulent kinetic energy $k$ and the turbulent dissipation rate $\varepsilon$. Their equations can be expressed as follows:

$$
\begin{gathered}
\nabla \cdot\left(\rho_{\text {mix }} V_{\text {mix }} k\right)=\nabla \cdot\left(\frac{\mu_{t, \text { mix }}}{\sigma_{k}} \nabla k\right)+G_{k, \text { mix }}-\rho_{\text {mix }} \varepsilon, \\
\nabla \cdot\left(\rho_{\text {mix }} V_{\text {mix }} \varepsilon\right)=\nabla \cdot\left(\frac{\mu_{t, \text { mix }}}{\sigma_{\varepsilon}} \nabla \varepsilon\right)+\frac{\varepsilon}{k}\left(c_{1} G_{k, \text { mix }}-c_{2} \rho_{\text {mix }}\right),
\end{gathered}
$$

where subscript of mix, indicating mixture and turbulent kinetic generation, is expressed as follows:

$$
G_{k, \text { mix }}=\mu_{t, \text { mix }}\left(\nabla V_{\text {mix }}+\left(\nabla V_{\text {mix }}\right)^{T}\right) .
$$

With constant values of $c_{1}=1.44, c_{2}=1.92, c \mu=0.09, \sigma_{\varepsilon}=$ $1.3, \sigma_{k}=1$.

The above equations are solved for the following boundary conditions. At inner tube inlet uniform velocity and temperature profile for $T_{\text {in }}=298 \mathrm{~K}$ are assumed. Pure

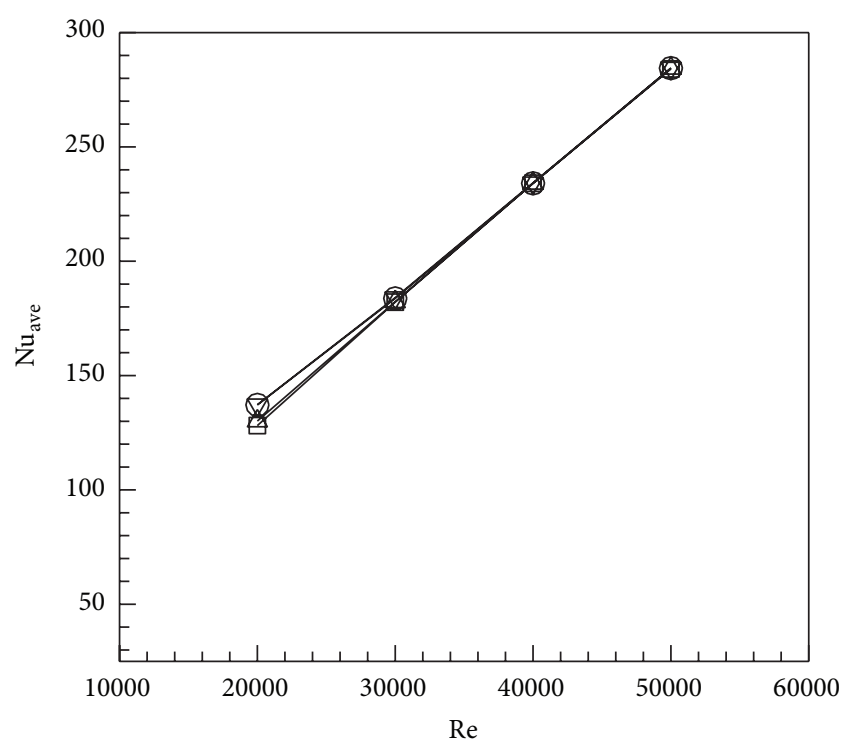

$\square$ Inner tube, 145800 cells $\quad \nabla$ Inner tube, 315000 cells $\triangle$ Inner tube, 238000 cells $\bigcirc$ Inner tube, 396000 cells

FIGURE 2: Different grids for independency of solution.

water enters in the annulus with uniform and constant velocity and temperature $V_{\text {in,an }}=2.407 \mathrm{~m} / \mathrm{s}$ and $T_{\text {in,an }}=$ $360 \mathrm{~K}$, respectively. Inner tube is without thickness and outer tube is thermally insulated. At tubes outlet fully developed conditions and on the walls, the nonslip conditions are considered. Moreover, a constant turbulent intensity, equal to $1 \%$, is imposed for both sides.

\section{Computational Procedure and Validation}

In the numerical solution, finite volume method is utilized for solving the above equations. PRESTO and QUICK scheme is used for pressure correction and volume fraction, respectively. For other equations second order upwind is adopted for numerical solution.

The SIMPLE algorithm is used for pressure-velocity coupling. Different nonuniform grids are tested to insure independency of solution (Figure 2). 315000 cells for inner tube is sufficient for the present study. Finer mesh is used near the wall because of higher velocity and temperature gradient. Mean Nusselt number is calculated as follows:

$$
\mathrm{Nu}=\frac{h_{\text {ave }} d}{k_{\text {eff }}} \text {. }
$$

In Figure 3 validation takes place with a correlation proposed by Dittus and Boelter [16] for pure fluid in turbulent pipe flow.

\section{Results and Discussions}

Results of numerical solution of convective heat transfer of $\gamma-\mathrm{Al}_{2} \mathrm{O}_{3}$ /water nanofluid in a tube with two-phase models of mixture and different volume concentration $(2,3,4$, and 6$)$ at turbulent flow are presented. The mean diameters of $\gamma-\mathrm{Al}_{2} \mathrm{O}_{3}$ 


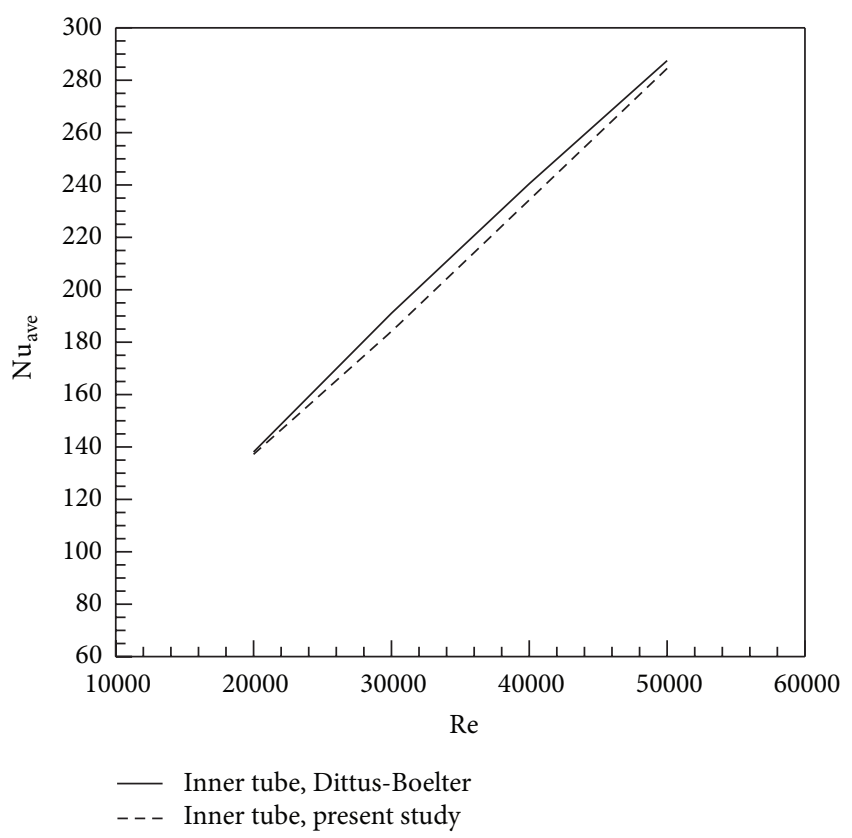

FIGURE 3: Grid validation for inner tube and annulus by correlation proposed by Dittus and Boelter [16].

nanoparticles are assumed to be $20 \mathrm{~nm}$. Fully developed (hydrodynamically and thermally) turbulent flow is assumed for inner tube for $L / D=65$ [17].

Constant velocity inlet and turbulent intensity for pure water equal to $2.407 \mathrm{~m} / \mathrm{s}$ and $1 \%$ are assumed for annulus for all runs.

Figure 4 depicts centerline turbulent kinetic energy for different nanoparticle volume fraction along the tube length. As shown in the figure, turbulent kinetic energy increases by increasing nanoparticle volume fraction. Also, results show fully developed region for $X / D=45$ for different nanoparticle volume fraction and pure water that proves nanofluid has no effects on fully developed length.

Heat transfer coefficient increases by augmenting nanoparticle volume fraction and Reynolds number, as depicted in Figure 5(a). A comparison between present study and experimental correlation proposed by Pak and Cho [5] showed that present study results are in good agreement with this correlation. As reported in the figure maximum convection coefficient can be achieved in maximum nanoparticle concentration and Reynolds number. Also, as shown in Figure 5(b), heat transfer coefficient enhances with an appropriate slope by increasing volume fraction of nanoparticle.

Despite an enhancement in heat transfer coefficient by increasing volume fraction, wall shear stress increases with increasing nanoparticle concentration (Figure 6) as reported by Bianco et al. [9].

Table 2 reports enhancing average heat transfer coefficient ratio in comparison to wall shear stress ratio. By augmenting nanoparticle volume fraction, convection heat transfer coefficient increases by lower slope than average wall shear stress. It seems that, for the highest concentration considered,

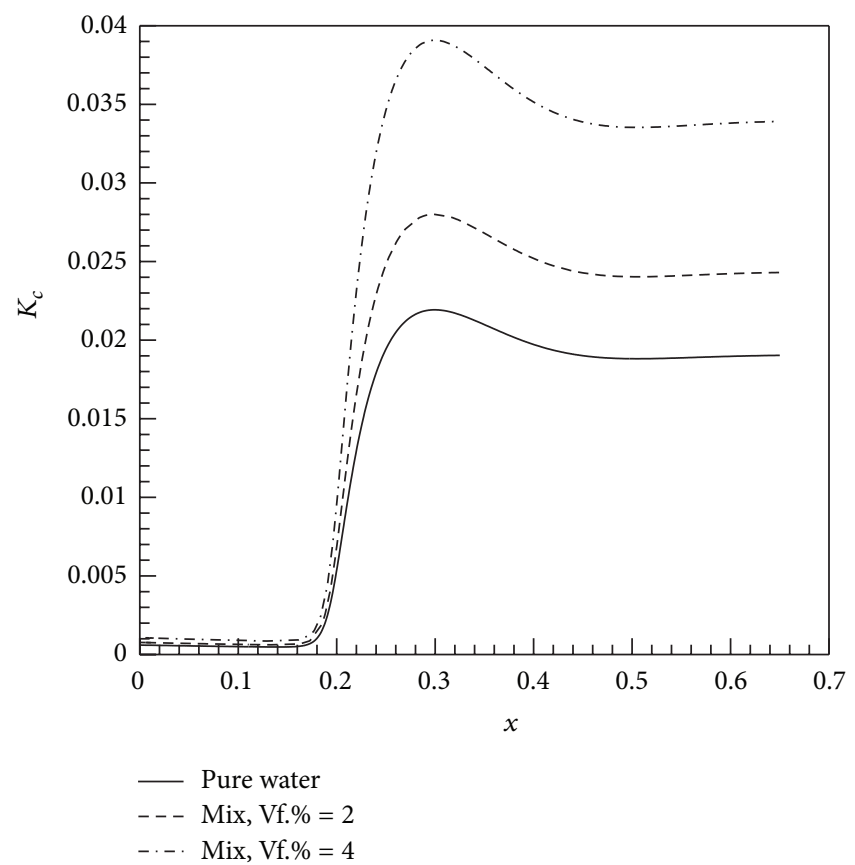

FIGURE 4: Centerline turbulent kinetic energy for different nanoparticle volume fraction at $\mathrm{Re}=20000$.

TABLE 2: Average heat transfer coefficient ratio in comparison to wall shear stress ratio.

\begin{tabular}{lcc}
\hline $\begin{array}{l}\text { Nanoparticle } \\
\text { volume fraction }\end{array}$ & $\left(h_{\mathrm{nf}} / h_{f}\right)\left(\gamma-\mathrm{Al}_{2} \mathrm{O}_{3}\right)$ & $\left(\tau_{\mathrm{nf}} / \tau_{f}\right)\left(\gamma-\mathrm{Al}_{2} \mathrm{O}_{3}\right)$ \\
\hline 0 & 1 & 1 \\
2 & 1.07 & 1.35 \\
3 & 1.12 & 1.63 \\
4 & 1.18 & 2 \\
6 & 1.32 & 3.02 \\
\hline
\end{tabular}

$\varphi=7 \%$, the increase in wall shear stress about 3 times bigger than base fluid (pure water) is achieved that proves using nanofluid at higher volume fractions is not appropriate.

Figure 7 illustrates turbulent kinetic energy distribution along the tube for fixed Reynolds number, $\operatorname{Re}=20000$, and different nanoparticle concentration. Because of higher velocity gradient in the vicinity of walls, the turbulent kinetic energy is high and then decreases by moving to center of tube. It is obvious that turbulent kinetic energy increases by augmenting nanoparticle volume fraction.

Dimensional velocity profile at $\mathrm{Re}=40000$ and different nanoparticle concentration is depicted in Figure 8 for a fixed value of Reynolds number; velocity increases by augmenting nanoparticle volume fraction. Effect of augmenting nanoparticle volume fraction on thermophysical properties of nanofluid is the reason for this increase in velocity.

\section{Conclusions}

In the present paper, turbulent forced convection of $\gamma$ $\mathrm{Al}_{2} \mathrm{O}_{3}$ /water nanofluid inside a double tube concentric heat 


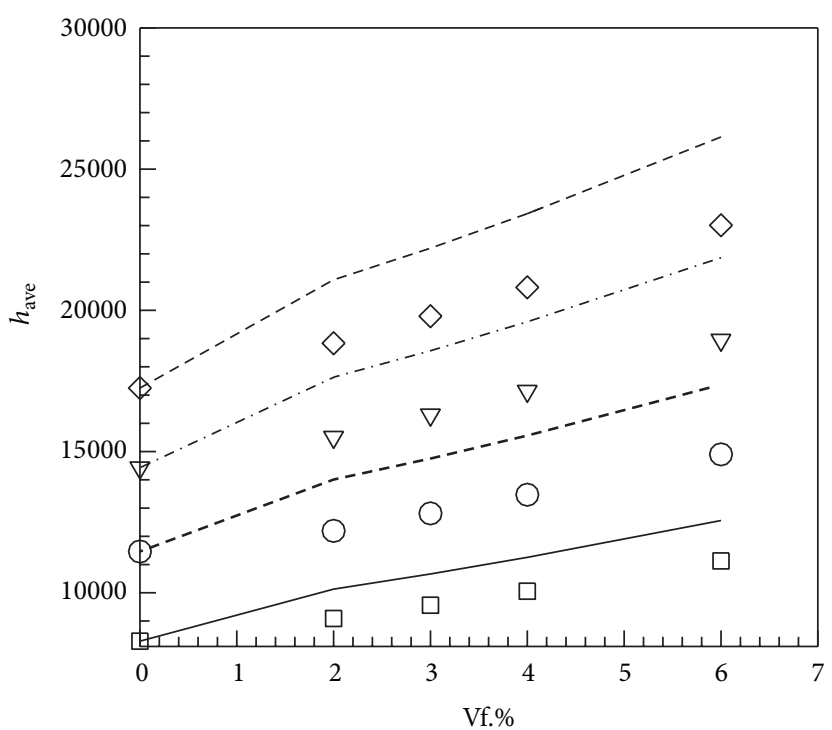

$\square \mathrm{Re}=20000$ (present study) $-\mathrm{Re}=20000($ Pak and Cho $)$ $\bigcirc \mathrm{Re}=30000$ (present study) - - $\mathrm{Re}=30000$ (Pakand Cho) $\nabla \mathrm{Re}=40000$ (present study) $-\cdot-\cdot \mathrm{Re}=40000$ (Pakand Cho) $\diamond \mathrm{Re}=50000$ (present study) $---\mathrm{Re}=50000$ (Pakand Cho)

(a)

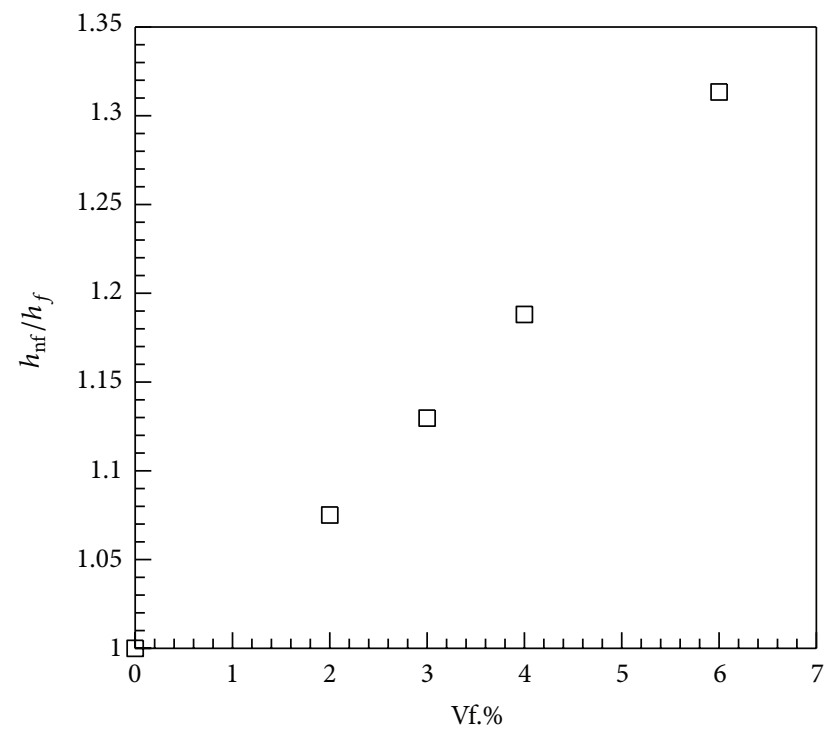

(b)

FIGURE 5: Effect of nanoparticle concentration on (a) average heat transfer coefficient and (b) heat transfer coefficient ratio.

exchanger was numerically investigated using mixture twophase approaches. A comparison with experimental correlation proposed by [5] showed numerical results are in good agreement with this correlation. The following results were obtained.

(i) Nanofluid has no effects on fully developed length with increasing nanoparticle concentration.

(ii) Heat transfer coefficient enhances by augmenting nanoparticle volume fraction as well as Reynolds

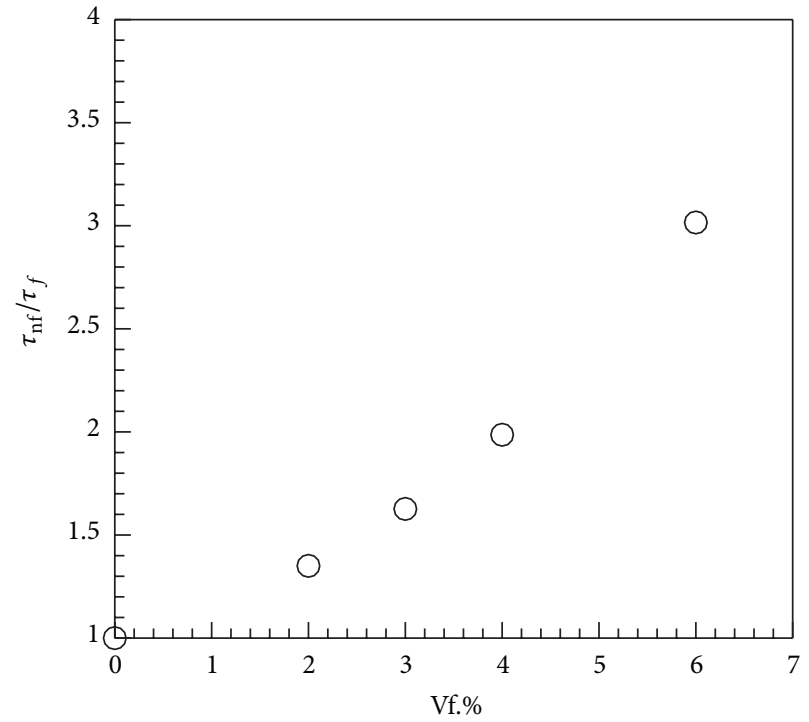

FIGURE 6: Effect of nanoparticle concentration on average wall shear stress ratio.
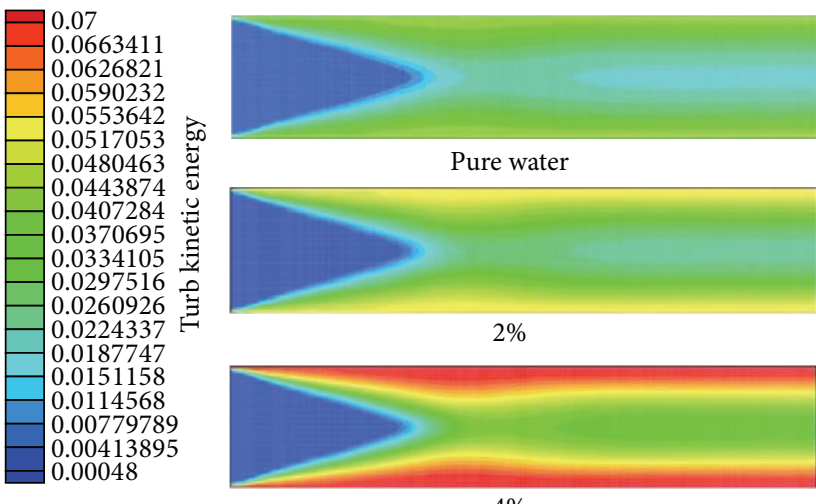

$4 \%$

FIGURE 7: Turbulent kinetic energy distribution along the tube for different nanoparticle concentration $(\operatorname{Re}=20000)$.

number. But, convection heat transfer coefficient increases by lower slope than average wall shear stress.

(iii) For a fixed value of Reynolds number, velocity profile increases by augmenting nanoparticle volume fraction.

\section{Notations}

$k$ : Thermal conductivity, $\mathrm{W} / \mathrm{m} \mathrm{K}$

$k_{b}$ : Boltzmann's constant

$d$ : Diameter, $m$

$h$ : Heat transfer coefficient, $\mathrm{W} / \mathrm{m}^{2} \mathrm{~K}$

Pr: Prandtl number, $\operatorname{Pr}=\mu c_{p} / k$

Re: Reynolds number, $\operatorname{Re}=\rho v d / \mu$

T: Temperature, $\mathrm{K}$

$V:$ Velocity, $\mathrm{m} / \mathrm{s}$

$P$ : Pressure, pa

$g$ : Gravitational acceleration, $\mathrm{m} / \mathrm{s}^{2}$. 


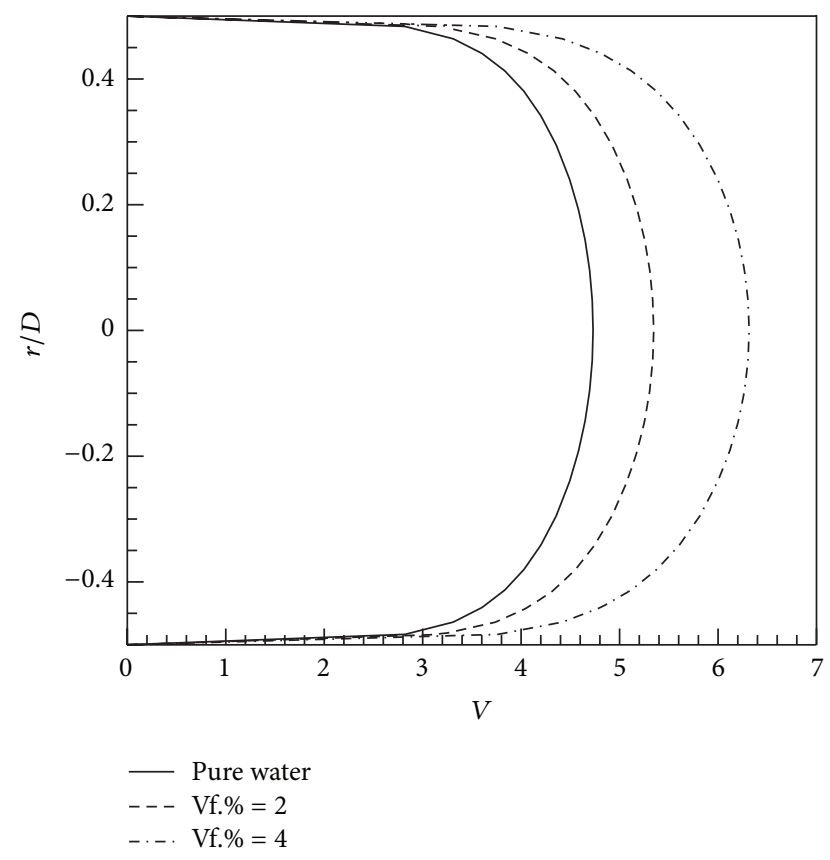

FIGURE 8: Effect of nanoparticle concentration on fully developed velocity profile for fixed $\mathrm{Re}=40000$.

\section{Greek Letters}

$\varphi$ : Particle volume concentration

$\rho$ : Fluid density, $\mathrm{kg} / \mathrm{m}^{3}$

$\mu$ : Fluid dynamic viscosity, $\mathrm{kg} / \mathrm{m} \mathrm{s}$

$\tau$ : Wall shear stress, $\mathrm{Pa}$.

\section{Subscripts}

\author{
nf: Nanofluid \\ b: Base fluid \\ p: Particle \\ eff: Effective properties.
}

\section{Conflict of Interests}

The author declares that there is no conflict of interests regarding the publication of this paper.

\section{References}

[1] H. Masuda, A. Ebata, K. Teramae, and N. Hishinuma, "Alteration of thermal conductivity and viscosity of liquid by dispersing ultra-fine particles (dispersion of $\gamma-\mathrm{Al}_{2} \mathrm{O}_{3}, \mathrm{SiO}_{2}$, and $\mathrm{TiO}_{2}$ ultra-fine particles)," Netsu Bussei, vol. 7, no. 4, pp. 227-233, 1993.

[2] S. U. S. Choi, "Enhancing thermal conductivity of fluids with nanoparticles," in Developments and Applications of Non-Newtonian Flows, ASME Publications FED-Vol. 231/MD-Vol. 66, pp. 99-105, The American Society of Mechanical Engineers, New York, NY, USA, 1995.
[3] S. Lee, S. U. S. Choi, S. Li, and J. A. Eastman, "Measuring thermal conductivity of fluids containing oxide nanoparticles," Journal of Heat Transfer, vol. 121, no. 2, pp. 280-289, 1999.

[4] X. Wang, X. Xu, and S. U. S. Choi, "Thermal conductivity of nanoparticle-fluid mixture," Journal of Thermophysics and Heat Transfer, vol. 13, no. 4, pp. 474-480, 1999.

[5] B. C. Pak and Y. I. Cho, "Hydrodynamic and heat transfer study of dispersed fluids with submicron metallic oxide particles," Experimental Heat Transfer, vol. 11, no. 2, pp. 151-170, 1998.

[6] Q. Li and Y. Xuan, "Convective heat transfer and flow characteristics of Cu-water nanofluid," Science in China, Series E: Technological Sciences, vol. 45, no. 4, pp. 408-416, 2002.

[7] S. E. B. Maïga, C. T. Nguyen, N. Galanis, and G. Roy, "Heat transfer behaviours of nanofluids in a uniformly heated tube," Superlattices and Microstructures, vol. 35, no. 3-6, pp. 543-557, 2004.

[8] V. Bianco, F. Chiacchio, O. Manca, and S. Nardini, "Numerical investigation of nanofluids forced convection in circular tubes," Applied Thermal Engineering, vol. 29, no. 17-18, pp. 3632-3642, 2009.

[9] V. Bianco, O. Manca, and S. Nardini, "Numerical investigation on nanofluids turbulent convection heat transfer inside a circular tube," International Journal of Thermal Sciences, vol. 50, no. 3, pp. 341-349, 2011.

[10] K. Khanafer and K. Vafai, "A critical synthesis of thermophysical characteristics of nanofluids," International Journal of Heat and Mass Transfer, vol. 54, no. 19-20, pp. 4410-4428, 2011.

[11] C. H. Chon, K. D. Kihm, S. P. Lee, and S. U. S. Choi, "Empirical correlation finding the role of temperature and particle size for nanofluid $\left(\mathrm{Al}_{2} \mathrm{O}_{3}\right)$ thermal conductivity enhancement," Applied Physics Letters, vol. 87, Article ID 153107, pp. 1-3, 2005.

[12] X. Wang, X. Xu, and S. U. S. Choi, "Thermal conductivity of nanoparticle-fluid mixture," Journal of Thermophysics and Heat Transfer, vol. 13, no. 4, pp. 474-480, 1999.

[13] M. Manninen, V. Taivassalo, and S. Kallio, "On the mixture model for multiphase flow," Technical Research Center of Finland 288, VTT Publications, 1996.

[14] L. Schiller and A. Naumann, "A drag coefficient correlation," Zeitschrift des Vereines Deutscher Ingenieure, vol. 77, pp. 318320, 1935.

[15] B.-E. Lauder and D.-B. Spalding, Lectures in Mathematical Models of Turbulence, Academic Press, London, UK, 1972.

[16] F. W. Dittus and L. M. K. Boelter, "Heat transfer in automobile radiators of the tubular type," International Communications in Heat and Mass Transfer, vol. 12, no. 1, pp. 3-22, 1985.

[17] F. P. Incropera, D. P. DeWitt, T. L. Bergman, and A. S. Lavine, Fundamentals of Heat and Mass Transfer, Wiley, 6th edition, 2006. 


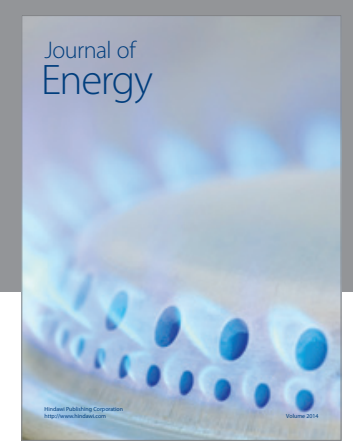

Journal of

Industrial Engineering
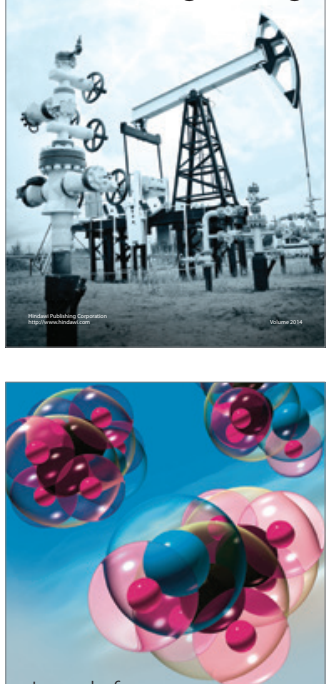

Fuels
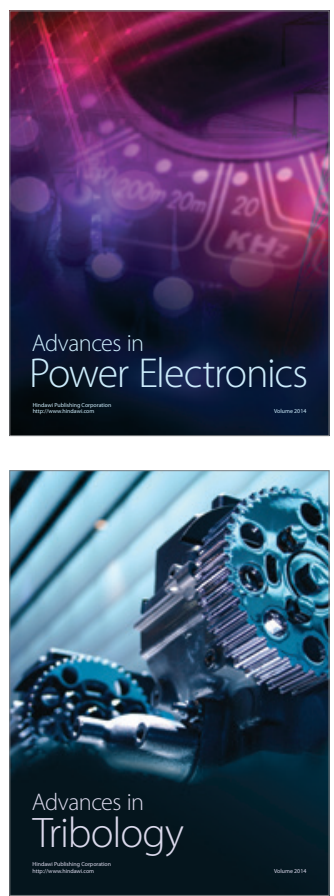

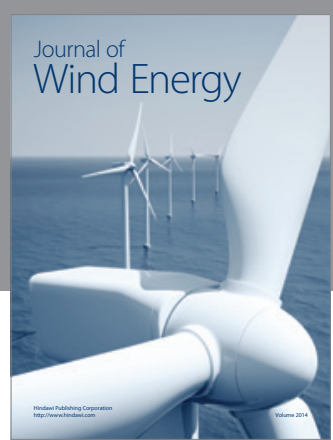

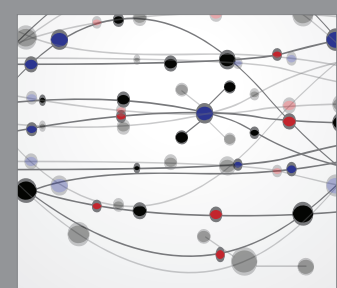

The Scientific World Journal

Submit your manuscripts at http://www.hindawi.com

Journal of

Structures
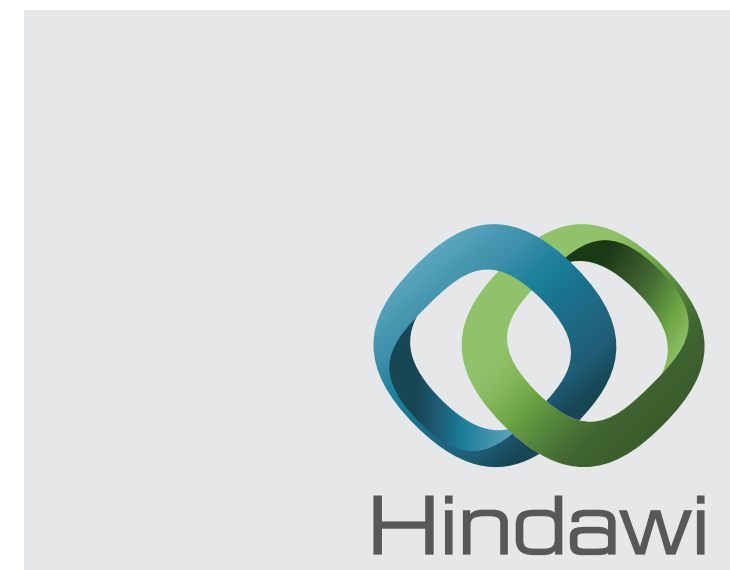

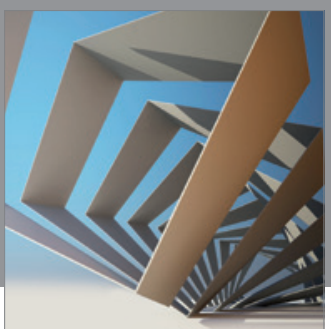

Rotating

Machinery
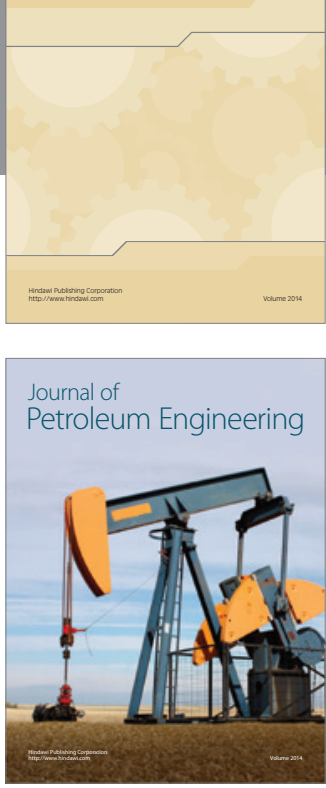

Journal of

Solar Energy
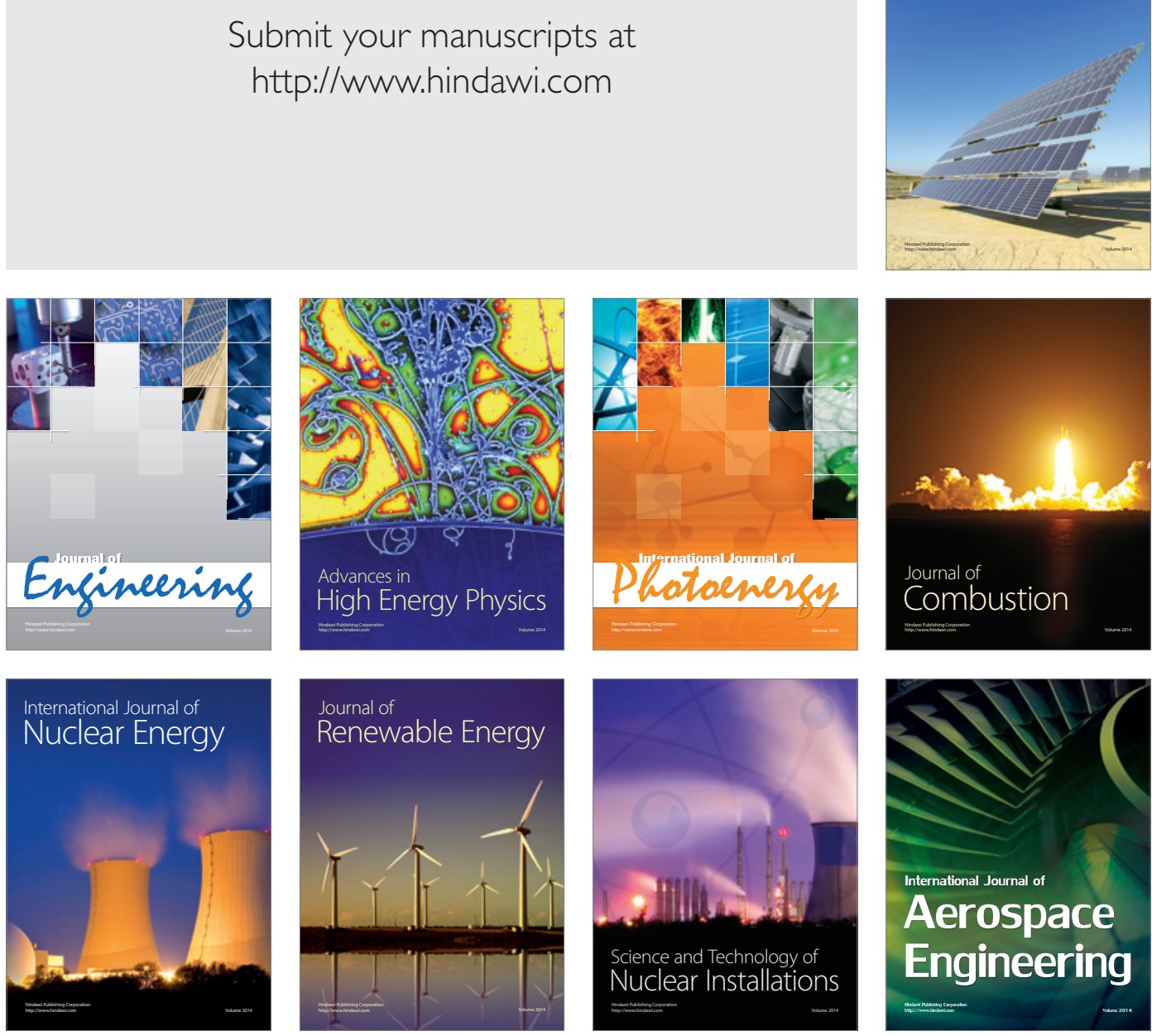